\title{
Endogenous growth I: Escaping diminishing returns
}

Filipe Campante, Federico Sturzenegger and Andrés Velasco

\section{Chapter 5 from}

\begin{tabular}{|c|c|}
\hline LSF perses & $\begin{array}{c}\text { Filipe Campante, } \\
\text { Federico Sturzenegger } \\
\text { and Andrés Velasco }\end{array}$ \\
\hline $\begin{array}{l}\text { ADVANCED MACRO- } \\
\text { ECONOMICS }\end{array}$ & $\begin{array}{c}\text { Advanced Macro- } \\
\text { economics }\end{array}$ \\
\hline 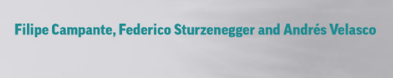 & SE Press \\
\hline
\end{tabular}

Suggested citation: Campante, Filipe; Sturzenegger, Federico; and Velasco, Andrés. (2021) 'Endogenous growth I: Escaping diminishing returns', in Filipe Campante, Federico Sturzenegger and Andrés Velasco, Advanced Macro-Economics: An Easy Guide. London: LSE Press, 2021. Chapter 5. https://doi.org/10.31389//sepress.ame.e 


\section{Endogenous growth models I: Escaping diminishing returns}

We are still searching for the Holy Grail of endogenous growth. How can we generate growth within the model, and not as an exogenous assumption, as in the Neoclassical Growth Model with exogenous technological progress? Without that, we are left unable to really say much about policies that could affect long-run growth. We have mentioned two possible approaches to try and do this. First, we can assume different properties for the production function. Perhaps, in reality, there are features that allow economies to escape the limitations imposed by diminishing returns to accumulation. Second, we can endogenise the process of technological change so we can understand its economic incentives. The former is the subject of this chapter, and we will discuss the latter in the next one.

\section{1 | The curse of diminishing returns}

You will recall that a crucial lesson from the Neoclassical Growth Model was that capital accumulation, in and of itself, cannot sustain long-run growth in per capita income. This is because of diminishing returns to the use of capital, which is a feature of the neoclassical production function. In fact, not only are there diminishing returns to capital (i.e. $\frac{\partial^{2} F}{\partial K^{2}}<0$ ) but these diminishing returns are strong enough that we have the Inada condition that $\lim _{K \rightarrow \infty} \frac{\partial F}{\partial K}=0$. Because of this, as you accumulate capital, the incentive to save and invest further will become smaller, and the amount of capital per worker will eventually cease to grow. The crucial question is: Are there any features of real-world technologies that would make us think that we can get away from diminishing returns?

\subsection{Introducing human capital}

We show, in the context of the Solow model, how expanding the concept of capital accumulation can generate endogenous growth. This, however, depends on total returns to accumulation being nondiminishing.

One possibility is that the returns to accumulation are greater than we might think at first. This is because there is more to accumulation than machines and plants and bridges. For instance, we can also invest in and accumulate human capital!

\section{How to cite this book chapter:}

Campante, F., Sturzenegger, F. and Velasco, A. 2021. Advanced Macroeconomics: An Easy Guide.

Ch. 5. 'Endogenous growth models I: Escaping diminishing returns', pp. 51-68. London: LSE Press.

DOI: https://doi.org/10.31389/lsepress.ame.e License: CC-BY-NC 4.0. 
Could that allow us to escape the curse, and achieve sustainable growth? Here is where a formal model is once again required. We will do that in the simplest possible context, that of the Solow model, but now introducing a new assumption on the production function: the presence of human capital as an additional factor. To fix ideas, let's go to the Cobb-Douglas case:

$$
Y=K^{\alpha} H^{\beta}(A L)^{\gamma} .
$$

Note that we are assuming the technological parameter $A$ to be of the labour-augmenting kind. It enters into the production function by making labour more effective. ${ }^{1}$ Dividing through by $L$ we obtain

$$
\frac{Y}{L}=A^{\gamma}\left(\frac{K}{L}\right)^{\alpha}\left(\frac{H}{L}\right)^{\beta} L^{(\alpha+\beta+\gamma)-1},
$$

where $\alpha+\beta+\gamma$ is the scale economies parameter. If $\alpha+\beta+\gamma=1$, we have constant returns to scale (CRS). If $\alpha+\beta+\gamma>1$, we have increasing returns to scale; doubling all inputs more than doubles output.

Assume CRS for starters. We can then write the production function as

$$
y=A^{\gamma} k^{\alpha} h^{\beta},
$$

where, as before, small-case letters denote per-capita variables.

\subsection{1 | Laws of motion}

Let us start way back in the Solow world. As in the simple Solow model, assume constant propensities to save out of current income for physical and human capital, $s_{k}, s_{h} \in(0,1)$. Let $\delta$ be the common depreciation rate. We then have

$$
\begin{aligned}
& \dot{K}=s_{k} Y-\delta K, \\
& \dot{H}=s_{h} Y-\delta H,
\end{aligned}
$$

and, therefore,

$$
\begin{aligned}
\frac{\dot{K}}{L} & =s_{k} y-\delta k, \\
\frac{\dot{H}}{L} & =s_{h} y-\delta h .
\end{aligned}
$$

Recall next that

$$
\begin{aligned}
& \frac{\dot{K}}{L}=\dot{k}+n k, \\
& \frac{\dot{H}}{L}=\dot{h}+n h .
\end{aligned}
$$

Using these expressions we have

$$
\begin{aligned}
& \dot{k}=s_{k} A^{\gamma} k^{\alpha} h^{\beta}-(\delta+n) k, \\
& \dot{h}=s_{h} A^{\gamma} k^{\alpha} h^{\beta}-(\delta+n) h,
\end{aligned}
$$


which yield:

$$
\begin{aligned}
& \gamma_{k}=\frac{\dot{k}}{k}=s_{k} A^{\gamma} k^{\alpha-1} h^{\beta}-(\delta+n), \\
& \gamma_{h}=\frac{\dot{h}}{h}=s_{h} A^{\gamma} k^{\alpha} h^{\beta-1}-(\delta+n) .
\end{aligned}
$$

\subsection{2 | Balanced growth path}

You will recall that a BGP is a situation where all variables grow at a constant rate. From (5.12) and (5.13) (and in the absence of technological progress), we see that constant $\gamma_{k}$ and $\gamma_{h}$ require, respectively ${ }^{2}$,

$$
\begin{aligned}
& (\alpha-1) \gamma_{k}+\beta \gamma_{h}=0, \\
& \alpha \gamma_{k}+(\beta-1) \gamma_{h}=0 .
\end{aligned}
$$

Substituting the second equation into the first equation yields

$$
\frac{1-\alpha-\beta}{1-\beta} \gamma_{k}=0
$$

But given CRS, we have assumed that $\alpha+\beta<1$, so we must have $\gamma_{k}=\gamma_{h}=0$. In other words, just as before, without technical progress ( $A$ constant), this model features constant per-capita capital $k$ and constant per-capita human capital $h$. No growth again! Of course, we can obtain long-run growth again by assuming exogenous (labour-augmenting) technological progress, $\frac{\dot{A}}{A}=g$. Consider a BGP in which $\frac{k}{k}$ and $\frac{h}{h}$ are constant over time. From (5.12) and (5.13), this requires that $\frac{k}{y}$ and $\frac{h}{y}$ be constant over time. Consequently, if a BGP exists, $y, k$, and $h$, must all be increasing at the same rate. When the production function exhibits CRS, this BGP can be achieved by setting $\frac{\dot{y}}{y}=\frac{\dot{k}}{k}=\frac{\dot{h}}{h}=g$. ${ }^{3}$ The longrun growth rate is thus independent of $s_{k}, s_{h}, n$ or anything that policy affects, unless $g$ is endogenised somehow. (But again, long-run levels of income do depend on these behavioural parameters.)

\section{\begin{tabular}{l|c} 
5.2.3 & Still looking for endogenous growth
\end{tabular}}

Why is the long-run growth rate still pinned down by the exogenous rate of technological growth as in the Solow Model? CRS implies that the marginal products of $K$ and $H$ decline as these factors accumulate, tending to bring growth rates down. Moreover, Cobb-Douglas production functions satisfy the Inada conditions so that, in the limit, these marginal products asymptotically go to 0 . In other words, CRS still keeps us in the domain of diminishing returns to capital accumulation, regardless of the fact that we have introduced human capital!

How can we change the model to make long-run growth rates endogenous (i.e., potentially responsive to policy)? You should see immediately from (5.16) that there is a possibility for a BGP, with $\gamma_{k}$ and $\gamma_{h}$ different from zero: if $\alpha+\beta=1$. That is to say, if we have constant returns to capital and human capital, the reproducible factors, taken together.

It is easy to see, from (5.12) and (5.13), that in a BGP we must have

$$
\frac{\dot{k}}{k}=\frac{\dot{h}}{h} \longrightarrow \frac{k^{*}}{h^{*}}=\frac{s_{k}}{s_{h}} .
$$


In other words, in a BGP $k$ and $h$ must grow at the same rate. This is possible since diminishing returns does not set in to either factor $(\alpha+\beta=1)$. What rate of growth is this? Using (5.17) in (5.12) and (5.13) we obtain (normalizing $A=1$ for simplicity)

$$
\frac{\dot{k}}{k}=\frac{\dot{h}}{h}=s_{h}\left(\frac{s_{k}}{s_{h}}\right)^{\alpha}-(\delta+n)=s_{k}^{\alpha} s_{h}^{1-\alpha}-(\delta+n) .
$$

The long-run (BGP) growth rate of output is

$$
\frac{\dot{y}}{y}=\alpha \frac{\dot{k}}{k}+(1-\alpha) \frac{\dot{h}}{h}=s_{k}^{\alpha} s_{h}^{1-\alpha}-(\delta+n) .
$$

Now $s_{k}, s_{h}$ do affect long-run growth. If policy affects these, then policy affects growth. For instance, increasing the savings rates leads to higher growth in the long run. In other words, when we have human capital and constant returns to reproducible factors of production, it is possible to explain longrun growth (see Figure 5.1).

Figure 5.1 Endogenous growth

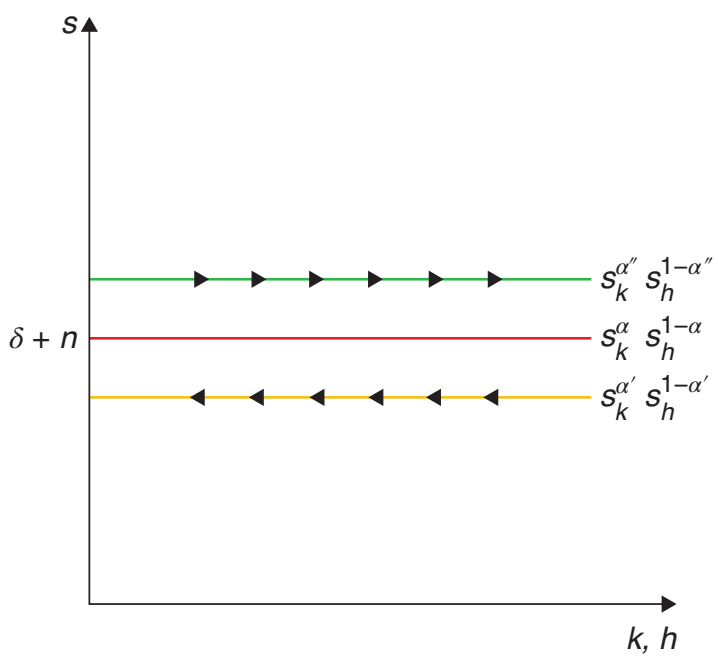

A couple of observations are in order. First, with permanent differences in growth rates across countries, the cross-national variation of per-capita incomes will blow up over time. In other words, there is no convergence in such a model. Also, if there is technical progress, growth rates will be higher.

\section{3 | The AK model}

We embed the notion of non-diminishing returns to accumulation into the setting of the Ramsey problem: $f(k)=A k$. The resulting Euler equation, $\frac{\dot{c}_{t}}{c_{t}}=\sigma(A-\rho)$, displays endogenous growth. This is a very different world from the NGM: there are no transitional dynamics, policies affect long-run growth, there is no convergence, and temporary shocks have permanent effects. 
The model in the previous section, just like the Solow model, was not micro-founded in terms of individual decisions. Let us now consider whether its lessons still hold in a framework with optimising individuals.

We have seen that the key aspect to obtaining long-run growth in the previous model is to have constant returns to reproducible factors when taken together. Including human capital as one such factor is but one way of generating that. To keep things as general as possible, though, we can think of all reproducible factors as capital, and we can subsume all of these models into the so-called AK model.

Consider once again a model with one representative household living in a closed economy, members of which consume and produce. There is one good, and no government. Population growth is 0 , and the population is normalised to 1 . All quantities (in small-case letters) are per-capita. Each consumer in the representative household lives forever.

The utility function is

$$
\int_{0}^{\infty}\left(\frac{\sigma}{\sigma-1}\right) c_{t}^{\frac{\sigma-1}{\sigma}} e^{-\rho t} d t, \rho>0
$$

where $c_{t}$ denotes consumption, $\rho$ is the rate of time preference and $\sigma$ is the elasticity of intertemporal substitution in consumption.

We have the linear production function from which the model derives its nickname:

$$
Y_{t}=A k_{t}, A>0
$$

Again, think of household production: the household owns the capital and uses it to produce output.

The resource constraint of the economy is

$$
\dot{k}_{t}=A k_{t}-c_{t} \text {. }
$$

\subsection{1 | Solution to household's problem}

The household's problem is to maximise (5.20) subject to (5.22) for given $k_{0}$. The Hamiltonian for the problem can be written as

$$
H=\left(\frac{\sigma}{\sigma-1}\right) c_{t}^{\frac{\sigma-1}{\sigma}}+\lambda_{t}\left(A k_{t}-c_{t}\right)
$$

Note $c$ is the control variable (jumpy), $k$ is the state variable (sticky), and $\lambda$ is the costate.

First order conditions are

$$
\frac{\partial H}{\partial c_{t}}=c_{t}^{-\frac{1}{\sigma}}-\lambda_{t}=0
$$




$$
\begin{gathered}
\dot{\lambda}_{t}=-\frac{\partial H}{\partial k_{t}}+\rho \lambda_{t}=-A \lambda_{t}+\rho \lambda_{t}, \\
\lim _{t \rightarrow \infty}\left(k_{t} \lambda_{t} e^{-\rho t}\right)=0 .
\end{gathered}
$$

This last expression is, again, the transversality condition (TVC).

\subsection{2 | At long last, a balanced growth path with growth}

Take (5.24) and differentiate both sides with respect to time, and divide the result by (5.24) to obtain

$$
-\frac{1}{\sigma} \frac{\dot{c}_{t}}{c_{t}}=\frac{\dot{\lambda}_{t}}{\lambda_{t}}
$$

Multiplying through by $-\sigma,(5.27)$ becomes

$$
\frac{\dot{c}_{t}}{c_{t}}=-\sigma\left(\frac{\dot{\lambda}_{t}}{\lambda_{t}}\right) .
$$

Finally, using (5.25) in (5.28) we obtain

$$
\frac{\dot{c}_{t}}{c_{t}}=\sigma(A-\rho),
$$

which is the Euler equation. Note that here we have $f^{\prime}(k)=A$, so this result is actually the same as in the standard Ramsey model. The difference is in the nature of the technology, as now we have constant returns to capital.

Define a BGP once again as one in which all variables grow at a constant speed. From (5.22) we get

$$
\frac{\dot{k}_{t}}{k_{t}}=A-\frac{c_{t}}{k_{t}} .
$$

This implies that capital and consumption must grow at the same rate - otherwise we wouldn't have $\frac{\dot{k}_{t}}{k_{t}}$ constant. And since $y_{t}=A k_{t}$, output grows at the same rate as well. From (5.29) we know that this rate is $\sigma(A-\rho)$. Hence,

$$
\frac{\dot{c}_{t}}{c_{t}}=\frac{\dot{k}_{t}}{k_{t}}=\frac{\dot{y}_{t}}{y_{t}}=\sigma(A-\rho) .
$$

Note, there will be positive growth only if $A>\rho$ that is, only if capital is sufficiently productive so that it is desirable to accumulate it.

Second, from (5.30) we see that along a BGP we must have

$$
y_{t}-c_{t}=\sigma(A-\rho) k_{t} \Rightarrow c_{t}=[(1-\sigma) A+\sigma \rho] k_{t}=\left[\frac{(1-\sigma) A+\sigma \rho}{A}\right] y_{t} .
$$

In words, consumption is proportional to capital. Or, put differently, the agent consumes a fixed share of output every period. Notice that this is much like the assumption made in Solow. If $s$ is the savings rate, here $1-s=\frac{(1-\sigma) A+\sigma \rho}{A}$, or $s=\sigma\left(\frac{A-\rho}{A}\right)$. The difference is that this is now optimal, not arbitrary.

There are no transitional dynamics: the economy is always on the BGP. 


\subsubsection{Closing the model: The TVC and the consumption function}

We must now ask the following question. Are we sure the BGP is optimal? If $A>\rho$, the BGP implies that the capital stock will be growing forever. How can this be optimal? Would it not be better to deplete the capital stock? More technically, is the BGP compatible with the TVC? Since we did not use it in constructing the BGP, we cannot be sure. So, next we check the BGP is indeed optimal in that, under some conditions, it does satisfy the TVC.

Using (5.24) the TVC can be written as

$$
\lim _{t \rightarrow \infty}\left(k_{t} c_{t}^{-\frac{1}{\sigma}} e^{-\rho t}\right)=0 .
$$

Note next that equation (5.29) is a differential equation which has the solution

$$
c_{t}=c_{0} e^{\sigma(A-\rho) t} .
$$

Combining the last two equations the TVC becomes

$$
\lim _{t \rightarrow \infty}\left(k_{t} c_{0}^{-\frac{1}{\sigma}} e^{-A t}\right)=0 .
$$

From the solution to expression (5.31) we have

$$
k_{t}=k_{0} e^{\sigma(A-\rho) t} .
$$

Using this to eliminate $k_{T}$, the TVC becomes

$$
\lim _{t \rightarrow \infty}\left(k_{0} c_{0}^{-\frac{1}{\sigma}} e^{\sigma(A-\rho) t} e^{-A t}\right)=\lim _{t \rightarrow \infty}\left(k_{0} c_{0}^{-\frac{1}{\sigma}} e^{-\theta t}\right)=0,
$$

where

$$
\theta \equiv(1-\sigma) A+\sigma \rho .
$$

Hence, for the TVC we need $\theta>0$, which we henceforth assume. Note that with logarithmic utility $(\sigma=1), \theta=\rho$.

\subsubsection{The permanent effect of transitory shocks}

In the $\mathrm{AK}$ model, as we have seen, growth rates of all pertinent variables are given by $\sigma(A-\rho)$. So, if policy can affect preferences $(\sigma, \rho)$ or technology $(A)$, it can affect growth.

If it can do that, it can also affect levels. From the production function, in addition to (5.31) and (5.32), we have

$$
\begin{gathered}
k_{t}=k_{0} e^{\sigma(A-\rho) t}, \\
y_{t}=A k_{0} e^{\sigma(A-\rho) t}, \\
c_{t}=[(1-\sigma) A+\sigma \rho] k_{0} e^{\sigma(A-\rho) t} .
\end{gathered}
$$

Clearly, changes in $\sigma, \rho$ and $A$ matter for the levels of variables. 
Notice here that there is no convergence in per capita incomes whatsoever. Countries with the same $\sigma, \rho$, and $A$ retain their income gaps forever. ${ }^{4}$

Consider the effects of a sudden increase in the marginal product of capital $A$, which suddenly and unexpectedly rises (at time $t=0$ ), from $A$ to $A^{\prime}>A$. Then, by (5.31), the growth rate of all variables immediately rises to $\sigma\left(A^{\prime}-\rho\right)$.

What happens to the levels of the variables? The capital stock cannot jump at time 0 , but consumption can. The instant after the shock $\left(t=0^{+}\right)$, it is given by

$$
c_{0^{+}}=\left[(1-\sigma) A^{\prime}+\sigma \rho\right] k_{0^{+}}>c_{0}=[(1-\sigma) A+\sigma \rho] k_{0^{+}},
$$

where $k_{0^{+}}=k_{0}$ by virtue of the sticky nature of capital.

So, consumption rises by $(1-\sigma)\left(A^{\prime}-A\right) k_{0}$. But, output rises by $\left(A^{\prime}-A\right) k_{0}$. Since output rises more than consumption, growth picks up right away.

It turns out that the AK model has very different implications from the Neoclassical Growth Model when it comes to the effects of transitory shocks. To see that, consider a transitory increase in the discount factor, i.e. suppose $\rho$ increases for a fixed interval of time; for simplicity, assume that the new $\rho$ is equal to $A$.

Figure 5.2 shows the evolution of the economy: the transitory increase in the discount rate jolts consumption, bringing growth down to zero while the discount factor remains high. When the discount factor reverts, consumption decreases, and growth restarts. But there is a permanent fall in the level of output relative to the original path. In other words, there is full persistence of shocks, even if the shock itself is temporary. You may want to compare this with the Neoclassical Growth Model trajectories (Figure 5.3), where there is catch-up to the original path and there are no long-run effects.

Figure 5.2 Transitory increase in discount rate

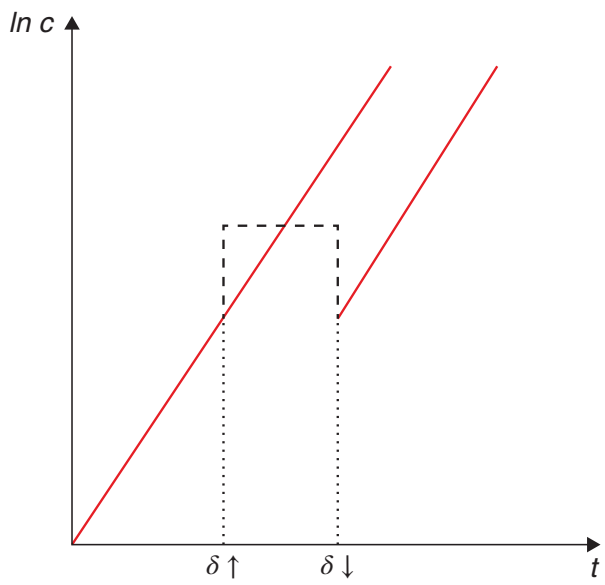

\subsubsection{In sum}

In AK models of endogenous growth:

1. There is no transitional dynamics;

2. Policies that affect the marginal product of capital (e.g. taxes) do affect growth;

3. There is no convergence;

4. Even temporary policies have permanent effects. 
Figure 5.3 Comparison with Solow model

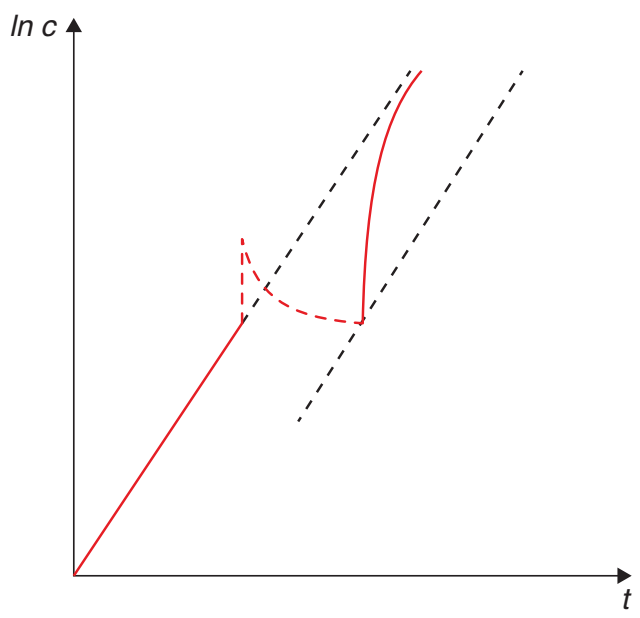

These results are surprising and were initially presented by Romer (1987), as part of the contributions that eventually won him the Nobel Prize in Economics in 2018. You have to admit that this is very different from the world of diminishing returns depicted by the NGM. Now look at the graph from the U.S. recovery after the Great Recession of 2008/2009 and notice the similarities with the dynamics of the AK model: no return to the previous growth trend. The graph even suggests that it is not the first time a pattern like this plays out. Maybe this model is onto something, after all.

Figure 5.4 U.S. real GDP and extrapolated trends

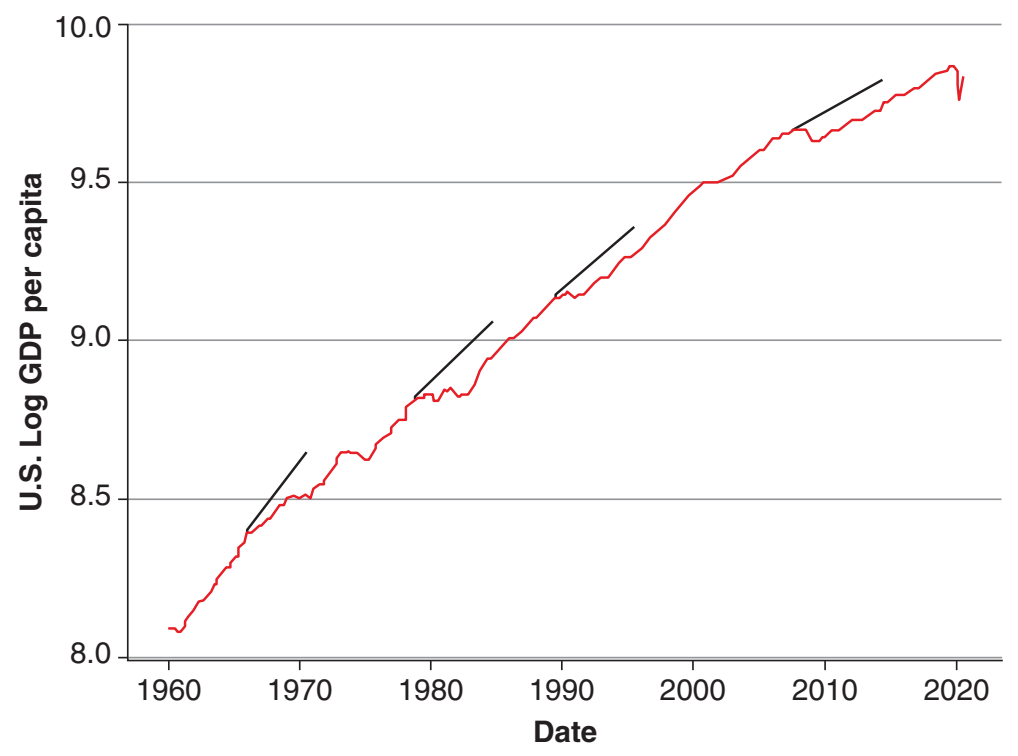




\subsection{Knowledge as a factor of production}

We argue that knowledge explains why accumulation may not face diminishing returns. We develop different models of how this may happen (learning-by-doing, specialisation). In the process, we show that in a world with non-diminishing returns to accumulation (and hence increasing returns to scale), the decentralised equilibrium need not be efficient: growth will be lower than than the social optimum as private incentives to accumulate knowledge are below the social returns.

We have seen that the key to obtaining long-run growth in our models is to get constant returns in the reproducible factors. But this begs the question: why do we think that this would actually be the case in reality?

As we have seen, a world of constant returns to reproducible factors is, actually, a world with increasing returns to scale (IRS) - after all, there is at least labour and technology in the production functions as well. But, this is a problem because IRS implies that our simple model with perfect competition doesn't really work anymore.

To see why, note that with perfect competition, each factor of production gets paid its marginal product - you know that from Econ 101. However, if the production function is

$$
F(A, X),
$$

where $X$ has constant returns, then we have

$$
F(A, X)<A \frac{\partial F}{\partial A}+X \frac{\partial F}{\partial X} .
$$

There is not enough output to pay each factor their marginal productivity!

We had sidestepped this discussion up to this point, assuming that technology was there and was left unpaid. But now the time has come to deal with this issue head-on.

In doing so, we will build a bridge between what we have learned about accumulation and what we have talked about when referring to productivity. The crucial insight again is associated with Paul Romer, and can be summarised in one short sentence: economies can grow by accumulating "knowledge".

But what drives the accumulation of knowledge? Knowledge is a tricky thing because it is difficult to appropriate, i.e. it has many of the properties of a public good. As you may remember, the two distinguishing characteristics of any good are

- Rivalry $\longrightarrow$ if I use it you can't.

- Excludability $\longrightarrow$ I can prevent you from using it.

Private goods are rival and excludable, pure public goods are neither. Technology/knowledge is peculiar because it is non-rival, although excludable to some extent (with a patent, for example).

The non-rivalry of knowledge immediately gives rise to increasing returns. If you think about it, knowledge is a fixed cost: in order to produce one flying car, I need one blueprint for a flying car, but I don't need a second blueprint to build a second unit of that flying car. In other words, one doesn't need to double all inputs in order to double output.

This complicates our picture. If factors of production cannot be paid their marginal returns, and there is not enough output to pay them all, then how is the accumulation of knowledge paid for? Here are the options: 
1. $A$ is public and provided by the government;

2. Learning by doing (i.e. externalities, again);

3. Competitive behaviour is not preserved.

We will not deal much with \# 1 (though it is clear that in the areas where research has more externalities and is less excludable, as in basic research, there is a larger participation of the public sector), but we will address some relevant issues related to \#2 (here) and \#3 (next chapter).

\subsection{1 | Learning by doing}

This was first suggested by Romer (1987). The idea is that you become better at making stuff as you make it: knowledge is a by-product of production itself. This means that production generates an externality. If each firm does not internalise the returns to the knowledge they generate and that can be used by others, firms still face convex technologies even though there are increasing returns at the level of the economy. It follows that competitive behaviour can be preserved.

Let us model this with the following production function,

$$
y=A k^{\alpha} \bar{k}^{\eta}
$$

where $\bar{k}$ is the stock of knowledge (past investment). Given this we compute the (private) marginal product of capital and the growth rate:

$$
\begin{gathered}
f^{\prime}(k)=A \alpha k^{\alpha-1} \bar{k}^{\eta}=A \alpha k^{\alpha+\eta-1}, \\
\gamma_{c}=\sigma\left(A \alpha k^{\alpha+\eta-1}-\rho\right) .
\end{gathered}
$$

We have endogenous growth if $\alpha+\eta \geq 1$. Notice that we need CRS in the reproducible factors, and, hence, sufficiently strong IRS. It is not enough to have IRS; we need that $\eta \geq 1-\alpha$.

For a central planner who sees through the learning-by-doing exercise:

$$
\begin{gathered}
f(k)=A k^{\alpha+\eta}, \\
f^{\prime}(k)=(\alpha+\eta) A k^{\alpha+\eta-1}, \\
\gamma_{p}>\gamma_{c} .
\end{gathered}
$$

It follows that the economy does not deliver the right amount of growth. Why? Because of the externality: private agents do not capture the full social benefit of their investment since part of it spills over to everyone else. This is a crucial lesson of the endogenous growth literature. Once we introduce IRS, there will typically be a wedge between the decentralised equilibrium and the optimal growth rate. 


\subsection{2 | Adam Smith's benefits to specialisation}

The second story, (from Romer 1990), suggests that economies can escape diminishing returns by increasing the range of things they produce, an idea akin to Adam Smith's suggestion that specialisation increases productivity. Suppose the production function could use a continuum of potential inputs.

$$
Y(X, L)=L^{1-\alpha} \int_{0}^{\infty} X(i)^{\alpha} d i
$$

But not all varieties are produced. Let's say only the fraction $[0, M]$ are currently available. Say the average cost of production of each intermediate unit is 1 , this implies that of each unit I will use

$$
X(i)=\bar{X}=\frac{Z}{M},
$$

where $Z$ are total resources devoted to intermediate inputs. So, this yields

$$
Y=L^{1-\alpha} M\left(\frac{Z}{M}\right)^{\alpha}=L^{1-\alpha} Z^{\alpha} M^{1-\alpha} .
$$

Note that we can write $Z=M \bar{X}$, so an expansion in $Z$ can be accomplished by increasing $M$, the number of varieties, or increasing $\bar{X}$, the amount of each variety that is used. In other words, you can either pour more resources into what you already do, or into doing different things. We can thus write

$$
Y=L^{1-\alpha}(M \bar{X})^{\alpha} M^{1-\alpha}=L^{1-\alpha} \bar{X}^{\alpha} M .
$$

Lo and behold: increasing $\bar{X}$ encounters diminishing returns $(\alpha<1)$, but that is not the case when one increases $M$. In other words, specialisation prevents diminishing returns. Choosing units appropriately, we can have

$$
M=Z \text {. }
$$

But this then yields

$$
Y=L^{1-\alpha} Z
$$

If $\dot{Z}=Y-C$ we are done: we are back to the AK model!

A nice example of the power of diversification in the production function is obtained in Gopinath and Neiman (2014), where they use Argentina's crisis of 2001/2002, which restricted access of firms to intermediate inputs, to estimate a large impact on productivity.

We should model next how the private sector will come up with new varieties (R\&D). This will typically involve non-competitive behaviour: one will only invest in R\&D if there is a way of recouping that investment (e.g. patents, monopoly power). This will also lead to a wedge between the optimal growth rate and the one that is delivered by the decentralised equilibrium: monopolies will undersupply varieties. But, careful: this will not always be so. In fact, we will develop a model where monopolies will oversupply varieties as well! At any rate, we will look at this in a bit more detail in the next chapter.

In the meantime, note in particular that these wedges introduce a potential role for public policy. For instance, if there is undersupply of varieties, one could introduce a subsidy to the purchase of intermediate inputs so that producers wouldn't face monopoly prices. 


\subsection{Increasing returns and poverty traps}

We digress into how a specific kind of increasing returns can be associated with the existence of poverty traps: situations where economies are stuck in a stagnating equilibrium when a better one would be available with an injection of resources. We discuss whether poverty traps are an important feature in the data and policy options to overcome them.

We have just argued that the presence of IRS (associated with non-diminishing returns to accumulation) is a key to understanding long-run growth. It turns out that the presence of (certain kinds of) IRS can also explain the condition of countries that seem to be mired in poverty and stagnation - as captured by the idea of poverty traps.

The concept of a poverty trap describes a situation in which some countries are stuck with stagnant growth and/or low levels of income per capita, while other (presumably similar) countries race ahead. The key for the emergence of this pattern is the presence of IRS, at least for a range of capital-labour ratios. The idea is as old as Adam Smith, but Rosenstein-Rodan (1943), Rosenstein-Rodan (1961), Singer (1949), Nurkse (1952), Myrdal and Sitohang (1957) and Rostow (1959) appropriated it for development theory. They argued that increasing returns only set in after a nation has achieved a particular threshold level of output per capita. Poor countries, they argued, were caught in a poverty trap because they had been hitherto unable to push themselves above that threshold. The implication is that nations that do not manage to achieve increasing returns are left behind. Those that do take off into a process of growth that leads to a steady state with higher standards of living (or maybe even to never-ending growth). You should keep in mind that, while the idea of poverty traps, and the calls for "big push" interventions to lift countries above the threshold that is needed to escape them, have been around for quite a while, they are still very much in the agenda. See for instance, Sachs (2005). Of course this view has plenty of critics as well - on that you may want to check Easterly (2001)'s book, which provides a particularly merciless critique.

Let's develop one version for a story generating poverty traps based on a simple modification of the Solow model highlighting the role of increasing returns in the production function. This makes the argument in the simplest possible fashion. You can refer to the paper by Kraay and McKenzie (2014) for a discussion of what could generate this sort of increasing returns. For instance, there could be fixed costs (lumpy investments) required to access a better technology (coupled with borrowing constraints). They also tell stories based on savings behaviour, or nutritional traps, among others.

\subsubsection{Poverty trap in the Solow model}

Recall that, in per capita terms, the change in the capital stock over time is given by

$$
\dot{k}=s \cdot f(k)-(n+\delta) \cdot k
$$

The key to generating growth traps in the Solow model is assuming a particular shape to the production function. In particular, we assume a (twice-continuously differentiable) function such that

$$
f^{\prime \prime}(k)=\left\{\begin{array}{c}
<0 \text { if } 0<k<k_{a} \\
>0 \text { if } k_{a}<k<k_{b} \\
<0 \text { if } k>k_{b} .
\end{array}\right.
$$


The key is that the production function $f(k)$ has a middle portion where it exhibits increasing returns to scale.

Notice that the term $\frac{s f(k)}{k}$, crucial for the dynamics of the Solow model, has a derivative equal to

$$
\frac{\partial \frac{s f(k)}{k}}{\partial k}=\frac{s k f^{\prime}(k)-s f(k)}{k^{2}}=\frac{s f^{\prime}(k)}{k}\left(1-\frac{f(k)}{k f^{\prime}(k)}\right) .
$$

This derivative can only be zero whenever $f^{\prime \prime}(k)=0$, which by (5.58) happens when $k=k_{a}$ and $k=k_{b}{ }^{5}$ It can also be shown that

$$
\frac{\partial^{2} \frac{s f(k)}{k}}{\partial k^{2}}= \begin{cases}>0 & \text { if } k=k_{a} \\ <0 & \text { if } k=k_{b}\end{cases}
$$

It follows that the function $\frac{s f(k)}{k}$ has the shape depicted in Figure 5.5.

Figure 5.5 Multiple equilibria in the Solow model

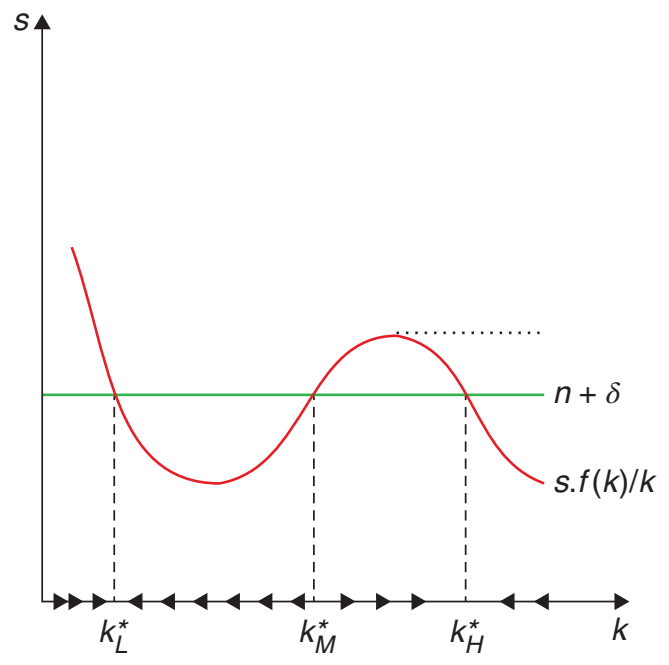

The dynamic features of this system, including the possibility of a poverty trap, can be read from the diagram directly. We have three steady states, at $k_{L}^{*}, k_{M}^{*}$ and $k_{H}^{*}$. Of these, $k_{L}^{*}$ and $k_{H}^{*}$ are stable, while $k_{M}^{*}$ is unstable. The implication is that if a country begins with a capital-labor ratio that is below $k_{M}^{*}$, then it will inexorably approach the steady state ratio $k_{L}^{*}$. If its initial capital-labour ratio is above $k_{M}^{*}$, then it will approach the much better steady state at $k_{H}^{*}$. The capital-labour ratio $k_{M}^{*}$, then, is the threshold capital stock (per capita) that a nation has to reach to take off and achieve the higher steady state.

Notice that in the end different countries may be at different steady state ratios, but they still exhibit identical growth rates (equal to zero). In Figure 5.5, a poor economy at steady state $k_{L}^{*}$ and a rich economy at steady state $k_{H}^{*}$ experience the same growth rates of aggregate variables and no growth in per capita variables. Notice, however, that the poor economy has per-capita income of $f\left(k_{L}^{*}\right)$ and the rich economy has per capita income of $f\left(k_{H}^{*}\right)$, which means that residents of the poor economy only get to enjoy consumption of magnitude $(1-s) f\left(k_{L}^{*}\right)$, while residents of the rich economy enjoy the higher 
level $(1-s) f\left(k_{H}^{*}\right)$. Hence, differences in initial conditions imply lasting differences in consumption and welfare among economies that are fundamentally identical. (Note that the production function $f(k)$, the savings rate $s$, the population growth rate $n$, and the depreciation rate $\delta$ are the same across these economies.)

\subsubsection{Policy options to overcome poverty traps}

There are a few alternative policy options for nations caught in a poverty trap. The first is to temporarily increase the savings rate. Consider Figure 5.5 and suppose that we have a country with savings rate $s_{1}$ stuck at the stagnant steady state ratio $k_{L}^{*}$. A rise in the savings rate will result in a situation where there is only one stable steady state ratio at a high level of $k^{*}$. Maintaining the higher savings rate for a while, the nation will enjoy a rapid rise in the capital-labour ratio towards the new steady state. However, it need not maintain this savings rate forever. Once the capital-labour ratio has gone past $k_{M}^{*}$, it can lower the savings rate back down to $s_{1}$. Then the country is within the orbit of the high capital-labour ratio $k_{H}^{*}$, and will move inexorably towards it by the standard properties of Solow adjustment. Thus, a temporary rise in the savings rate is one way for a nation to pull itself out of the poverty trap.

Similarly, another way of escaping this poverty trap is to temporarily lower the population growth rate. A nation stuck at $k_{L}^{*}$ could move the horizontal schedule down by decreasing population growth temporarily, thereby leaving a very high $k^{*}$ as the only steady-state capital-labour ratio. The old population growth can be safely restored once the Solovian dynamics naturally push the economy above $k_{M}^{*}$.

There is an obvious third possibility, beyond the scope of the country and into the realm of the international community, to provide a country that is mired in a poverty trap with an injection of capital, through aid, that increases its capital stock past the threshold level. This is the big push in aid advocated by some economists, as well as many politicians, multilateral organisations, and pop stars.

In all of these cases, you should note the permanent effects of temporary policy. You will recall that this is a general feature of growth models with increasing returns, and this illustrates the importance of this aspect for designing policy.

\subsubsection{Do poverty traps exist in practice?}

While many people believe poverty traps are an important phenomenon in practice - thereby providing justification for existing aid efforts - the issue is very controversial. Kraay and McKenzie (2014) consider the evidence, and come down on the skeptical side.

First, they argue that the kind of income stagnation predicted by poverty trap models are unusual in the data. The vast majority of countries have experienced positive growth over recent decades, and low-income countries show no particular propensity for slower growth. Since standard models predict a threshold above which a country would break free from the trap, that indicates that most countries would have been able to do so.

Second, they argue that the evidence behind most specific mechanisms that have been posited to generate poverty traps is limited. For instance, when it comes to the fixed cost story we have mentioned, it seems that for the most part individuals don"t need a lot of capital to start a business, and the amount of capital needed to start a business appears relatively continuous.

This doesn't mean, however, as they recognise, that poverty traps cannot explain the predicament of some countries, regions, or individuals. Being stuck in a landlocked country in an arid region is actually terrible! Also, we shouldn't conclude from the relatively sparse evidence that aid, for instance, 
is bad or useless. Poverty may be due to poor fundamentals, and aid-financed investments can help improve these fundamentals. But, it should temper our view on what we should expect from these policy interventions.

\subsection{What have we learned?}

We have seen that long-term growth is possible when accumulation is not subject to diminishing returns, and that this entails a world where there are increasing returns to scale. We have also argued that one key source of these increasing returns to scale, in practice, is the accumulation of knowledge: you do not have to double knowledge in order to double output. This in turn requires us to think about what drives knowledge accumulation, and we have seen a couple of alternative stories (learning-bydoing, specialisation) that help us think that through.

Very importantly, we have seen that a world of increasing returns is one that is very different from the standpoint of policy. There is no convergence - we shouldn't expect poor countries to catch up with rich countries, even when they have the same fundamental parameters. By the same token, temporary shocks have permanent consequences. This has disheartening implications, as we shouldn't expect countries to return to a pre-existing growth trend after being hit by temporary negative shocks. But it also has more cheerful ones as temporary policy interventions can have permanent results.

We have also seen how these lessons can be applied to a specific case of increasing returns, which can generate poverty traps. Whether such traps are widespread or not remains a source of debate, but the concept nevertheless illustrates the powerful policy implications of increasing returns.

\subsection{What next?}

To learn more about the endogenous growth models that we have started to discuss here, the book by Jones and Vollrath (2013) provides an excellent and accessible overview. Barro and Sala-i-Martin (2003) also covers a lot of the ground at a higher technical level that should still be accessible to you if you are using this book - it's all about the dynamic optimisation techniques we have introduced here.

For a policy-oriented and non-technical discussion on growth, an excellent resource is Easterly (2001). As we have mentioned, he is particularly skeptical when it comes to big push aid-based approaches. On poverty traps, it is worth noting that there are many other stories for sources of increasing returns of the sort we discussed. A particularly interesting one is studied by Murphy et al. (1989), which formalises a long-standing argument based on demand externalities (e.g. Rosenstein-Rodan (1943)) and investigates the conditions for their validity. This is a remarkable illustration of how helpful it is to formally model arguments. Another powerful story for increasing returns (and possible traps) comes from Diamond (1982), which studies how they can come about when market participants need to search for one another, generating the possibility of coordination failures. We will return to related concepts later in the book, when discussing unemployment (Chapter 16).

\section{Notes}

${ }^{1}$ Again, you should be able to see quite easily that in a Cobb-Douglas production function it doesn't really matter if we write $Y=A_{1} K^{\alpha} H^{\beta}(L)^{\gamma}$ or $Y=K^{\alpha} H^{\beta}\left(A_{2} L\right)^{\gamma}$; it is just a matter of setting 
$A_{1} \equiv A_{2}^{\gamma}$, which we can always do. It is important for the existence of a BGP that technology be labour-augmenting - though this is a technical point that you shouldn't worry about for our purposes here. You can take a look at Barro and Sala-i-Martin (2003) for more on that.

2 Take logs and derive with respect to time.

${ }^{3}$ Check the math! Hint: log-differentiate (5.1).

${ }^{4}$ Here, for simplicity, we have set population growth $n$ and depreciation $\delta$ to zero. They would also matter for levels and rates of growth of variables. In fact, introducing depreciation is exactly equivalent to reducing $A$ - you should try and check that out!

${ }^{5}$ Recall that the function is twice-continuously differentiable, such that $f^{\prime \prime}$ has to be zero at those points. To see why $f^{\prime \prime}(k)=0$ implies that (5.59) is equal to zero, recall from Econ 101 that "marginal product is less (more) than the average product whenever the second derivative is negative (positive)". It's all tied to Euler's homogenous function theorem, which is also behind why factors cannot be paid their marginal products when there are increasing returns to scale. As usual in math, it's all in Euler (or almost).

\section{References}

Barro, R. J. \& Sala-i-Martin, X. (2003). Economic growth (2nd ed.). MIT press.

Diamond, P. A. (1982). Aggregate demand management in search equilibrium. Journal of Political Economy, 90(5), 881-894.

Easterly, W. (2001). The elusive quest for growth: Economists' adventures and misadventures in the tropics. MIT press.

Gopinath, G. \& Neiman, B. (2014). Trade adjustment and productivity in large crises. American Economic Review, 104(3), 793-831.

Jones, C. I. \& Vollrath, D. (2013). Introduction to economic growth. WW Norton \& Company, Inc. New York, $N Y$.

Kraay, A. \& McKenzie, D. (2014). Do poverty traps exist? Assessing the evidence. Journal of Economic Perspectives, 28(3), 127-48.

Murphy, K. M., Shleifer, A., \& Vishny, R. W. (1989). Industrialization and the big push. Journal of Political Economy, 97(5), 1003-1026.

Myrdal, G. \& Sitohang, P. (1957). Economic theory and under-developed regions. London: Duckworth.

Nurkse, R. (1952). Some international aspects of the problem of economic development. The American Economic Review, 42(2), 571-583.

Romer, P. M. (1987). Growth based on increasing returns due to specialization. The American Economic Review, 77(2), 56-62.

Romer, P. M. (1990). Endogenous technological change. Journal of Political Economy, 98(5, Part 2), S71-S102.

Rosenstein-Rodan, P. N. (1943). Problems of industrialisation of eastern and south-eastern Europe. The Economic Journal, 53(210/211), 202-211.

Rosenstein-Rodan, P. N. (1961). Notes on the theory of the 'big push'. Economic development for Latin America (pp. 57-81). Springer.

Rostow, W. W. (1959). The stages of economic growth. The Economic History Review, 12(1), 1-16.

Sachs, J. (2005). The end of poverty: How we can make it happen in our lifetime. Penguin UK.

Singer, H. W. (1949). Economic progress in underdeveloped countries. Social Research, 1-11. 